\title{
Entre el tópico y la reivindicación: la instrumentalización de Gibraltar por el pensamiento conservador español
}

\author{
ISIDRO SEPÚlVEDA MUÑoz
}

La soberanía fáctica que del peñón e istmo de Gibraltar ostenta Gran Bretaña desde 1704 se ha ido convirtiendo para los españoles con los siglos más que en un problema, en una obsesión. La restitución de Gibraltar a la soberanía española se ha tenido presente por todos los españoles desde el momento en que se firmó el trágico Tratado de Utrech. En palabras de Madariaga, "el problema de Gibraltar no es tanto cosa que los españoles definen, sino cosa que define a los españoles. Que España quiera Gibraltar no puede ni discutirse. No seria España si no lo quisiera.» ${ }^{1}$

Si ante la redacción de constituciones, elección de monarcas e implantación de repúblicas, formación de gobiernos o plasmación de proyectos de reforma de cualquier campo y modalidad los españoles estuvieron enfrentados hasta llegar a la guerra civil, el tema de Gibraltar siempre ha presentado una unanimidad de posturas difícil de encontrar en cualquier momento de la historia de España.

La unanimidad se ha dado desde anglófilos ${ }^{2}$-José de Carvajal o Azcárate- a anglófobos -el marqués de la Ensenada y Martín Melgar-; realistas -Floridablanca o Goicoechea- y republicanos -Salmerón, Castelar o el mismo Azaña-; conservadores -Cánovas y Maura-, liberales -Sagasta, Moret, Romanones-, tradicionalistas -Vázquez de Mella-, radicales -Lerroux-, socialistas -Prieto-, comunistas -Maurin-, anarquistas -Monseny-, falangistas -José Antonio Primo de Rivera, Ruiz de Alda o

Madariaga, S.: Spain; London, Jonathan Cape, 1942; pág. 457

2 Es curiosa la postura de Espartero, cuya demanda de unanimidad no es sólo ante el tema, si no absoluta, lo que hace imposible su reivindicación: "Mientras España esté empobrecida y los partidos no se unan en una aspiración común para las cuestiones puramente nacionales, dejando a salvo las diferencias políticas, creo ocioso que se ponga el dedo en la llaga". FERNÁNDEZ Garcia, A.: Gibraltar (Ecos de la Patria); Málaga, Biblioteca Andaluza, 1884. 
Serrano Súñer-. La nómina de literatos, publicistas e intelectuales de las más variadas ramas que han manifestado, algunos con gran extensión e influencia, su opinión sobre el tema es muy numerosa. Gobiernos de las más dispares ideologias han presentado sin solución de continuidad reclamaciones que sistemáticamente han sido desoídas, cuando no ignoradas. Esta unanimidad, que no uniformidad, ante el contencioso la sintetizó crudamente Sánchez Albornoz, con la entereza que la legitimidad de su trayectoria le otorgaba:

«Podemos desear los españoles esta o aquella victoria, el triunfo de tal o cual ideología, el afianzamiento de éste o del otro sistema político o social. Pero no puede haber un español, digno de tal nombre, capaz de escribir, sin sonrojarse, que Gibraltar no es España. $Y$ si hay alguno que pueda escribirlo sin sonrojo, yo me tomo la libertad de sonrojarme por él, como español, liberal y en destierro" ${ }^{3}$.

Ante esta unanimidad de posturas sobre Gibraltar podrá preguntarse si es posible hacer una diferenciación entre las reivindicaciones de los conservadores, sean éstos autoritarios o constitucionalistas, y las demás fuerzas ideológicas. Si bien el objetivo explícito en todos ellos es común, como se ha visto, a la práctica totalidad del espectro político español, no es tan semejante el fin último de las demandas. Es difícil equiparar, por ejemplo, dos campañas coetáneas como las de José Antonio Primo de Rivera y la de Madariaga.

Tema adecuado para la retórica efectista y las muestras de exaltado patriotismo, el trabajo presente sólo pretende tratarlo ( $y$ no es ambición menuda) desde el punto de vista de la historia de las ideas. Más concretamente, estudiar el papel que la reivindicación de Gibraltar ha tenido en el pensamiento conservador español.

El presente trabajo analiza la evolución de las ideas que sobre el tema de la reivindicación española de Gibraltar se han ido produciendo. Para ello se ha utilizado un esquema metodológico que descompone las reivindicaciones en factores menores, más manejables en su tratamiento y evidenciadores de las diferencias existentes en el conjunto de las demandas. Básicamente este esquema se forma atendiendo a tres factores: la determinación de los orígenes del problema, la exposición de los medios susceptibles de encontrar una solución y la delimitación de los objetivos finales perseguidos.

3 Sanchez Albornoz, C.: De Carlomagno a Roosevelt; Buenos Aires, Emecé, 1943; pág. 104. 
En la primera fase se localiza el núcleo primigenio sobre el que se levanta cada una de las posturas, donde se define el origen del conflicto. A continuación se exponen los medios que los autores demandaban para llevar a cabo su reclamación. Y finalmente se señalan los objetivos que se persiguen con ella; éstos pueden ser (aunque no es necesario que aparezcan en todos los casos) de tres tipos: el objetivo explícito, fin por el que se promueve la campaña, se efectúan actuaciones o se hace mera publicística; el objetivo efectivo, razón por la que se realizan las demandas de un modo particular y en un momento concreto; y el objetivo subliminal, razón última y general, fin perseguido y por el cual se han efectuado los dos anteriores.

\section{NÚCLEO PRIMIGENIO}

La soberanía británica sobre el Peñón como hecho consumado ha sido presentada básicamente de dos modos. El primero buscó el origen y causa de esa soberanía por los medios del derecho internacional; los tratados firmados por España y Gran Bretaña durante el siglo XVIII fueron tomados como punto de partida sobre el que era necesario centrar la actuación. El segundo modo de abordar el problema de Gibraltar era la exposición diacrónica del efecto histórico de los tratados; de ese modo se consideraba el Peñón como un asunto exclusivamente de soberanía: una parte del territorio nacional estaba bajo posesión de una potencia extranjera.

\section{a) Una bandera y la cláusula de un tratado}

La base jurídica que Gran Bretaña ha expuesto desde inicios del siglo XVIII para mantener bajo su pabellón Gibraltar se ha basado en los tratados de Utrech (1713), Sevilla (1729) y Versalles (1783). Prácticamente todos los autores y políticos que han trabajado sobre el tema hicieron referencia a ellos, si bien de modo muy diverso.

Los autores y políticos conservadores y tradicionalistas abordan el tratado de Utrech de un modo secundario; los de Sevilla y Versalles apenas varían a su juicio el estatuto de la Roca y es en el primero donde se encuentra la argumentación básica. No es casualidad que apenas aportaran nada a este argumento hasta la mitad del presente siglo, basando sus comentarios en segundas lecturas y en argumentaciones que autores de distintas ideologias habian elaborado previamente. Esto se debe a que los autores progresistas (generalización en la que se incluye el amplio espectro desde liberales hasta comunistas) señalaron la toma juridica de la 
Roca y el tratado de Utrech como origen del problema, siendo la cláusula $X$ del tratado la piedra angular que sostenía el Peñón ${ }^{4}$.

El análisis del tratado y su larga décima cláusula han sido abordados desde todos los sectores. La finalidad de dicho análisis ha sido doble; por un lado demostrar su reiterado incumplimiento por parte británica, lo que haría necesaria la denuncia del tratado. La prueba del incumplimiento británico reiteradamente señalada fue la paulatina extensión del territorio que Utrech le otorgaba; esta ampliación se había desarrollado en tres periodos principalmente, coincidentes con momentos en que España "volvía la espalda" a causa de acontecimientos graves: dominio napoleónico, guerra hispano-norteamericana y guerra civil española. La costa este del Peñón, las aguas jurisdiccionales de la bahía de Algeciras y el istmo (con la construcción de un aeropuerto) eran las adquisiciones que hacian del marco del tratado un instrumento inválido, por reiterada violación británica ${ }^{5}$.

La segunda dimensión no es excluyente si no que se suma a la primera en su mismo objetivo de denunciar el tratado; es la corriente que niega la vigencia de éste basándose en el cambio de las bases jurídicas y políticas en que se sostuvo su formulación, es decir el recuerdo de la fórmula «rebus sic stantibus» inherente a todo tratado basado en el Derecho internacional ${ }^{6}$.

Para contrarrestar esta dominación de facto, basada en las cláusulas de Utrech, se han articulado varios argumentos. El más extremo ha sido el que niega la validez del tratado mismo ${ }^{7}$. Otra de las argumentaciones más debatidas, y en ocasiones repetida sin verdadero conocimiento, fue la de negar la

4 Esta posición, que habia sido comenzada a formar durante la República, se aconsejó que el gobierno franquista la declarara "con la adecuada solemnidad"; AGUINAGA, J. M": Cuadernos de política internacional española: Gibraltar; Archivo del Ministerio de Asuntos Exteriores (AMAE), Leg. R-5499 bis, exp. 7; págs. 112-113.

s Dada la evidencia del argumento fueron numerosos los autores que lo trataron y aún más los que reprodujeron en sus páginas la famosa cláusula. El mejor tratamiento del tema lo hizo el norteamericano WILBUR C. AвBOT en 1934: An Introduction to the Documents Relating to the International Status of Gibraltar. En el campo conservador las aportaciones más importantes las realizaron JuDERIAS, J.: Gibraltar, Apuntes para la historia de la perdida de esta plaza, de los sitios que le pusieron los españoles y de las negociaciones entre España e Inglaterra referentes a su restitucion, 1704-1796: Madrid, Imp. de Revista de Archivos y Bibliotecas y Museos, 1915. IBÁN̄E2 DE IBERO, C.: El Mediterráneo y la cuestión de Gibraltar; San Sebastián, Editorial Española, 1939 (donde se compara con la situación juridica e histórica de las plazas africanas de España). Lleonart, A.: Del Gibraltar inglés: su inconsistencia legal e histórica; Madrid [Punta Europa], 1968.

6 BARCIA Trelles, C.: “La vena yugular del Imperio Británico»; $A B C, 14-111-1954$; pág. 49.

7 LION DEPETAE, J.: "Gibraltar ante el derecho internacional"; $A B C, 28$ de agosto de 1954; pág. 11. "Gibraltar y el tratado de Utrech"; $A B C, 25$ de noviembre de 1954, p. 15. “España, Utrech, Gibraltar": $A B C, 18$ de diciembre de 1955; pág. 8. AREILZA, J. Ma: "Gibraltar, llave de España": Mundo Hispánico, nº 74, mayo de 1954 
cesión de soberanía por parte española con la firma de los tratados del siglo $\mathrm{XVIII}$; se aducía que en ellos se traspasaba la propiedad sobre la fortaleza y la base militar para su uso, pero no la soberanía, la potestad de jurisdicción ${ }^{8}$.

\section{b) "Una espina clavada en el corazón de España"}

Una gran parte de los autores de las campañas reivindicativas consideraron el origen de la cuestión gibraltareña desde el punto de vista de la soberanía nacional violada: una parte del territorio nacional permanecia bajo pabellón extranjero. Dicha postura, tan numerosa como general, ha sido matizada desde puntos de vista muy diversos y con efectos a si mismo dispares.

La frase que da título a este apartado, adjudicada a Felipe $V$, encierra ya ese mismo significado de dolor en el cuerpo, pero también en el espíritu, y lo más importante para algunos, en el orgullo. Decía León y Castillo que «el pabellón inglés sobre el Peñón es un pie británico sobre el cuello de la nacionalidad española ${ }^{9}$, y es determinante la frase de José Antonio al exclamar que "España confina al sur con una vergüenza». Este entender el problema de Gibraltar desde un punto de vista victimista ${ }^{10} \mathrm{O}$ de vergüenza nacional " tenía como objetivo señalar la ineludible "misión» de su recuperación; pero a diferencia del apartado anterior, no era para subsanar los abusos cometidos mediante el uso de un tratado, si no para lavar la afrenta y recuperar el honor ultrajado ${ }^{12}$. Este argumento no fue exclusivo

s Juderias, J.: Op. cit., Majo Framis, R.: "Gibraltar y el tratado de Utrech"; Africa, abril de 1954; pág. 17. “Pequeño examen de una usurpación»; La Vanguardia Española, 18.II.1954; pág. 5. Yangua Messía, J.: "Gibraltar"; $A B C, 4$.VIII.1954.

9 LEON Y CASTILLO, F:: Mis tiempos, Madrid, Libreria de Sucesores de Hernando, 1921; pág. 15.

10 Fanez, A. (sed.): Gibraltar, herida abierta; Madrid, Ediciones Mon, s.a. Ledesma Ramos, R.: Discurso a las juventudes de España; Madrid, Ediciones "La Conquista del Estado", 1935; págs. 68.72 .

11 "[Los pueblos castellanos vieron] con lágrimas de indignación y vergüenza, flotar en Menorca y en Gibraltar el pabellón de Inglaterra (sic). ¡Jamás vinieron sobre nuestra raza mayores afrentas!" Menéndez Pelayo, M.: Historia de los heterodoxos españoles; 2a ed. Madrid, Lib. de Victorino Suárez, 1930; tomo VI, pág. 34. Este fue el argumento de Primo de Rivera, sobre la "dolorosa realidad de [...] la ocupación del Peñón por los ingleses"; ésta era "más vejatoria que peligrosa; nos duele más que nos daña, ver ondear en el solar de nuestra patria un pabellón extranjero". Primo de Rivera, M.: Discursos leidos ante la Real Academia Hispano-Americana en la recepción pública de...; Cádiz, Imp. Manuel Alvarez, 1917; págs. 4 y 16.

12 S.A.: Gibraltar; Pamplona, Excma. Diputación Foral de Navarra, 1954. S.A.: Gibraltar es pañol. Reseña gráfica de una parte de nuestro territorio nacional; Barcelona, Ed. Patria, 1940. Malvasia, G.: Gibraltar por la razón o por la fuerza; Madrid, Maisal, 1979. PIÑAR, B.: La España irredenta: Gibraltar; Madrid, s.e., 1965. FANEZ, A.: Gibraltar, herida abierta; Madrid, Mon, s.a. 
de los conservadores, si bien las demás corrientes hicieron más hincapié en la cuestión del decoro y la dignidad nacional y mucha menos en el orgullo-honra o afrenta-vejación ${ }^{13}$.

En esta misma línea otro punto tomado como originario para la exposición del problema fue lo que Luis Aranguren llamó «anacronismo histórico» 14: la supervivencia de un residuo de la política imperialista inglesa en una etapa histórica que repudia tales actuaciones. Dicho argumento tuvo una amplia utilización durante toda la etapa franquista, apoyado principalmente por el repliegue del gran imperio británico a partir del término de la II guerra mundial; razón también por la que con anterioridad apenas se dio ${ }^{15}$. Complementaria a este punto fue la importancia dada desde el exterior a este anacronismo, remarcando además el hecho de que era «España la única nación europea en cuyo territorio tiene una colonia otra potencia extranjera» ${ }^{16}$. Este argumento del anacronismo ha venido siendo utilizado desde los años sesenta en las negociaciones con el Reino Unido; durante la transición y el reinicio de las conversaciones bajo el gobierno socialista se ha potenciado la utilización de tal argumento.

Otro punto originario del problema, sin contradecir a quienes aseguraban que “dolía más que perjudicaba», es señalado por quienes ponen especial énfasis en los perjuicios que la presencia británica en Gibraltar tiene para España. Los perjuicios señalados fueron, a causa de los diferentes intereses o preocupaciones, muy diversos. Los más trascendentes fueron aquellos que hacían referencia a las dimensiones económicas, geoestratégicas y sociales. En cuanto a la primera, comenzó a manifestarse a principios de siglo, dado que fue en los últimos años del xix cuando se evidenciaron las causas: contrabando -en numerosas ocasiones de armas-, emigración ilegal, competencia comercial con puertos cercanos, etc.

"Habria España olvidado que Gibraltar es carne y sangre suya, y se lo recordaría él a cada instante con los perjuicios que le causa, competidor de

Azcarate, G.: "Gibraltar", España; 23. IV. 1915; pág. 2.

ARANGUREN, L.: «El anacronismo de Gibraltar»; Excelsior (México D.F.), 27 y 28. VII. 1953.

Un articulo que tuvo una gran influencia en este punto fue FEDERZON, L.: "Hegemony in the Mediterranean", Foreing Affairs, vol. 14, $n^{\circ} 3$, abril de 1936; el autor italiano estudia los continuos enmascaramientos de la política exterior británica en el Mediterráneo, que presenta su conducta como fruto de principios éticos reduciendo la importancia de sus intereses materiales. Ejemplo de la utilización de este argumento durante el franquismo en BARCIA TRELLES, C.: "Gibraltar: supervivencia anacrónica", $A B C, 16.111 .1954 ;$ pág. 17.

is JESSEN, O.: Die Strasse von Gibraltar, Berlín, 1927; pág. 58. La importancia de esta cita, ya recogida con anterioridad, estuvo en encabezar el capítulo que dedicaron al tema AREILZA, J.M $M^{\mathfrak{a}}$ Y Castiella, F.M ${ }^{*}:$ Reivindicaciones de España; 2: ed. Madrid, Instituto de Estudios politicos, 1941. 
sus puertos en el comercio, sangría de sus rentas mediante el contrabando, puerta por donde se marchan clandestinamente emigrantes que no podrian irse por otra parte sin faltar a la ley, matricula en la que libremente se inscriben como inglesas embarcaciones que se dedican a fraudes contra nuestro tesoro o a conducción subrepticia de armas para la morisma a la otra rivera del Estrecho; obstáculo a que la bahía de Algeciras se fortifique contra los ataques de terceros" ${ }^{17}$.

Los perjuicios geoestratégicos de la presencia británica en el Peñón eran aun más importantes y fueron denunciados desde el último tercio del siglo $x \mid x$, coincidiendo con la paulatina implantación de la necesidad de una expansión colonial por el norte africano. Ya Labra, a pesar de su anglofilia, desde el Congreso denunció el cinismo del Reino Unido y la necesidad de acabar con la ocupación; Joaquín Costa dedicó todo un libro a estudiar las posibilidades españolas en Marruecos; pero ante el Estrecho, "que nos une como si fuera un río», Gibraltar era una reivindicación "necesaria e inaplazable " ${ }^{18}$. La influencia británica entorpecía la natural expansión por tierras africanas, pues se mantenia que un dominio absoluto del norte africano comprometería de modo definitivo la supervivencia inglesa en el Peñón ${ }^{19}$.

Esta argumentación evidenciaba que para buena parte de los autores del periodo de la Restauración hasta la Dictadura de Primo de Rivera Gibraltar era más un medio que el fin de su campaña; el verdadero propósito era el control del Estrecho, sin su dominio la política exterior y el progreso económico de España estarían siempre supeditados a una potencia extranjera ${ }^{20}$. El argumento del perjuicio geoestratégico fue retomado en los años sesenta por Castiella, bien que impregnado de los planteamientos gaullistas sobre autonomia de la politica exterior nacional; desde

17 Gonzalez Hontoria, M.: “Gibraltar», $A B C, 23.1 \mathrm{~V} .1915$, pág. 11. Un estudio del entramado socio-económico de Gibraltar y su campo en Garcia Venero, M.: Viaje a la España de Gibraltar, Málaga, Jefatura Provincial del Movimiento, 1955.

${ }_{18}$ Costa, J.: Intereses de España en Marruecos; Madrid, Imp. Fontaner, 1884.

19 En la necesidad española de controlar el norte de Marruecos no cabian "más resoluciones entre moros y cristianos que ser dominados o dominadores"; pero "España no logrará resolver la cuestion de Marruecos, con arregio a sus intereses y aspiraciones, interín no arregle de un modo definitivo la cuestión de Gibraltar". OLıvE, M.: Aspiraciones nacionales de España: Parte I: Gibraltar; Vigo, Imp. “El Imparcial», 1890; págs. 9 y 21.

20 HUGET DE VILLAR, DE: Bases para la política exterior de España; Tip. "la Académica", 1918. Un estudio desde el punto de vista estratégico militar en GUTIERREZ SOBRAL, J.: Estrecho de Gibraltar, Madrid, Imp. Ricardo F. Rojas, 1913. Gibraltar como ofensa, amenaza y centro de perturbación internacional para España en CORDERo TORRES, J.M ${ }^{a}$ : Relaciones exteriores de España (Problemas de la presencia española en el mundo); Madrid, Ediciones Movimiento, 1954. La pervivencia de este núcleo primigenio hasta la actualidad en Sal.afranca ORTEgA, J.: Melilla y Ceuta en su encrucijada de Gibraltar, Málaga, [el autor], 1983. 
ese punto de vista, la importancia de Gibraltar radicaba no en que la soberanía española estuviera ausente del Peñón, sino en que una potencia extranjera tenía una base en él, devaluando la posición estratégica de España en el Estrecho.

A todo lo anterior hay que añadir las indicaciones sobre los perjuicios sociales que la colonia británica acarreaba para España. Su exposición se centró, además de una serie de reflexiones sobre el pesimismo y el sentimiento de inferioridad que dicho estado de cosas generaba en todo español, en el Campo de Gibraltar. Comenzó a ser utilizado este argumento cuando Gran Bretaña, tras la segunda guerra mundial incorporó a sus derechos para continuar en la Roca los de los habitantes de Gibraltar. Desde esferas gubernamentales se contrargumentó señalando el estado de explotación en que vivían los miles de trabajadores españoles que sostenían la economía gibraltareña; desde la publicística se llegó a tener para con ellos un doble sentimiento de solidaridad nacional y desprecio por servir al bando contrario ${ }^{21}$.

Un último perjuicio, sólo expuesto desde las línea conservadoras como tal, es el que atañe a la seguridad religiosa y a la «civilización» española, atacadas por el influjo de la Roca. Menéndez Pelayo señalaba Gibraltar como «la primera tierra ibera en que libremente imperó la herejía, ofreciendo fácil refugio a todos los disidentes de la Península en los siglos XVIII y XIX, y centro estratégico de todas las operaciones de la propaganda anglo-protestante", tesis repetida en numerosas obras, religiosas y seglares, añadiendo la queja por el incumplimiento del tratado de Utrech, que garantizaba el mantenimiento exclusivo de la Iglesia Católica; como contraste, Madariaga no parece sentir quebranto alguno al señalar -erróneamente- el origen gibraltareño de la masonería española ${ }^{22}$.

\section{MEDIOS}

Una vez señalados los núcleos primigenios que se tomaron para el tratamiento del problema gibraltareño, siendo evidente y constante el objetivo

21 Garcia Venero, M.: Op. cit.; págs. 14 y 39; denuncia la explotación, pero también el deseo de parasitismo de La Línea, "este apretado caserio, que tiene algo de ceniciento y gris [...] obra de los ingleses" con "el doble fin de tener a sueldo brazos laboriosos y agentes de contrabando". Dicha argumentación fue muy abundante en los años cincuenta y sesenta; puede verse sintetizada junto a las anteriores en CASTIELLA, J.Må: Razones de España sobre Gibraltar, [Madrid], s.e., 1966.

22 Menendez Pelayo, M.: Op. cit.; págs. 36-37. Madariaga, S.: El ocaso del imperio español en América; Buenos Aires, Ed. Sudamericana, 1955; págs. 119-120. 
explícito de toda campaña u obra: la recuperación del territorio de Gibraltar; es necesario estudiar los medios por los cuales se pretendía alcanzar ese objetivo. Dado que tras casi tres siglos el pabellón británico sigue ondeando sobre la Roca es obvio señalar que los medios expuestos fueron en su mayoría exclusivamente teóricos. Las escasas ocasiones en que se llevaron a la práctica (los asedios y asaltos del siglo xvill y las negociaciones - «conversaciones" para el lado británico- en la segunda mitad del xx) no han tenido ningún resultado positivo.

La división entre autores y políticos que ya se operaba al tratar de encontrar la raíz del conflicto, se multiplica a la hora de diseñar un estrategia mediante la que obtener la recuperación del territorio. Métodos muy variados que van desde la belicosidad extrema a la más pacífica negociación, desde las exposiciones más razonadas hasta el más peregrino arbitrismo.

Un primer medio de recuperación fue la anulación de la importancia de Gibraltar mediante el desarrollo no sólo del campo circundante, si no nacional. Ya se vio la postura de Espartero, exigente de una España lejana de su coetáneo empobrecimiento para conseguir la recuperación de Gibraltar; ese mismo medio fue solicitado por Antonio Ríos Rosas, Francisco Serrano y Jorge Aragón ${ }^{23}$. Desde su particular campaña de regeneración nacional, Ganivet contemplaba Gibraltar como símbolo de la decadencia, pero también como medio para la recuperación nacional: "Gibraltar es una fuerza para Inglaterra mientras España sea débil, pero si España fuera fuerte se convertiria en un punto flaco y perdería su razón de ser» ${ }^{24}$.

Dada la inmensa labor que este medio imponía para la recuperación del Peñón se confió en medios más rápidos y efectivos. El más seguido, mucho más de 10 que pudiera parecer vista la superioridad manifiesta británica, fue el intento de recuperación-reconquista militar. Joaquín Santamaría y Pizarro presentó a la Real Academia de Historia un ensayo, Historia del último sítio de Gibraltar, donde se da repaso a sesenta y siete proyecto ideados a lo largo del siglo xIX para conseguir la rendición de Gibraltar ${ }^{25}$. Desde finales del XIX los adelantos artilleros hacían que la

\footnotetext{
23 ARAgon, J.: La cuestión de Gibraltar (Apuntes historicos); Madrid, Isidoro Morales, 1915; poniendo especial énfasis en el desarrollo del Campo de Gibraltar como medio de articular una igualdad entre ambos lados de la frontera. Este artificial medio de borrar la frontera paradójicamente fue seguido por quienes en 1954 hicieron esta frontera más visible que nunca al "cerrar la verja", convertido ya el argumento en una mera señal de prestigio.

24 Ganivet, A.: ldearium español; Granada, Tip. de Viuda e Hijos de Sabatel, 1897, pág. 94.

25 Armangue Rius, G.: Gibraltar y los españoles; Madrid, Aguilar, 1964.
} 
toma de la plaza no fuera necesariamente una cuestión de sitio o asalto, si no de fortificación de los alrededores, especialmente de la bahía de Algeciras ${ }^{26}$. Dado que la fuerza de Gibraltar radicaba según numerosos autores en la armada británica y fue por el mar la pérdida de la plaza, correspondía a la marina su recuperación ${ }^{27}$. Finalmente no faltó quien presentara la posibilidad de un ataque directo ${ }^{28}$. Hay que señalar que dicho medio de recuperación no fue exclusivo de los conservadores; el mismo Azaña llegó a abrir un expediente para preparar militarmente "los planes necesarios para tener aquel dominio» ${ }^{29}$. Pero el realismo, en última instancia revestido de pacifismo, apaciguó los ánimos aún en las circunstancias más propicias para un ataque ${ }^{30}$.

Si militarmente era irrecuperable y la posesión inglesa del Peñón era un inconveniente para el desarrollo español se vio la necesidad de articular otros mecanismos. Uno de los que contaron con las simpatías inglesas (al menos durante buena parte de los siglos XVIII y $x \mid x$ ) fue el cambio de Gibraltar por alguna plaza africana que dominara el Estrecho; dicha posibilidad fue expuesta sobre todo por liberales y anglófilos ${ }^{31}$, pero nunca

25. NavarRo TOMAS, M.: Importancia militar de Gibraltar y medios de que dispone España para anuiarla; Madrid, imp. del Cuerpo de Artilleria, 1896; éste estudio fue reeditado, no por casualidad, en sus Obras Completas en 1916 en medio de una fuerte controversia sobre la oportunidad de recuperar Gibraltar. Bentabol y URETA, H.: Presente y porvenir de Ceuta y Gibraltar, Madrid, Imp. de "Revista de Navegación y Comercio", 1894. Una importante y seria revisión de este plan fue realizado por MARTinez CAMPOS, C.: "A Dios rogando..."; Revista de Estudios Politicos, marzo-abril de 1954, págs. 103-114. Pervivencia de este medio durante la Transición en MaLvasia, G.: Gibraltar: Por la razón o por la fuerza; Madrid, Maisal, 1979.

27 Herrman, G.: Gibraltar, puerta del Mediterráneo; Santander, Cultura Española, 1938; traducción y prólogo de Juan José López lbor. Abundando en los medios expuestos en el texto, el prologuista pedía el aprovechamiento de la coyuntura y el fortalecimiento de la Marina: “jBarcos, Señor, muchos barcos, aunque para tenerlos tengamos que multiplicar los ayunos!» (p. 14).

28 VAzQuez SANZ, J.: España ante Inglaterra. Gibraltar, Barcelona, Tall. Tip. de Angela Ortega, 1940. Baeza Mancebo, A.: La hora de Gibraltar, s.1, Ed. Toledo, 1942.

${ }^{29}$ "Nuestro derecho a preparar la defensa nacional no puede supeditarse a nada. [En un Consejo de Ministros] hablé de la necesidad de sostener un ideal nacional, que sostenga la moral pública y el espíritu de los organismos del Estado, empezando por el Ejército. Los ministros estuvieron de acuerdo". AZAÑA, M:: Obras Completas; tomo IV, pág. 331; reproducido en ARMangue Rius, G.: Op. cit.

${ }_{30}$ Un simple ejemplo de esta linea: « iGibraltar! Yo solo, sin ser coronel, desde la sierra carbonera, con un cañón Ordónez, arrojaria al mar a los ingleses. Pero no cumple a la hidalguia nuestra herir por la espalda a quien, por enemigo que fuese, está empeñado en una lucha de vida y honra". León Roman, R.: Europa trágica /1-Centinelas del Rin; Madrid, Renacimiento, 1917; pág. 205.

31 «El puerto de Ceuta ofreceria a Inglaterra una base naval análoga a la del Peñón andaluz, y tendria, además en manos de esa gran nación, un valor extraordinario desde todos los puntos de vista. Para España todo serian ventajas". AzCÁAATE, G.: "Convenio entre España y Francia relativo a Marruecos"; Diario de Sesiones del Congreso de los Diputados, pág. 5.990; Gaceta, n²05, 1912. Reproducido en Aamangue Rius, G.: Op. cit. Luis de Zulueta ampliaba esta posición,añadiendo que "reducia de una manera honrosa nuestros compromisos en Marruecos"; en "Gibraltar, ¿un ideal o un sueño?", España, 16.IV.1915; pág. 2. 
contó con amplias simpatías. Fueron mucho más numerosos los testimonios que condenaron este medio de recuperación por dañar el prestigio o la propiedad nacional, por reproducir el problema o incluso agravarlo con el traslado o sencillamente al dar por supuesta la negativa británica ${ }^{32}$.

Dada la importancia de la recuperación y la inviabilidad de la permuta no faltó quien ya desde finales del siglo xIX expusiera la posibilidad de un arreglo económico ${ }^{33}$. Por los mismos motivos del canje, esta posibilidad encontró numerosos detractores, pero dichos planes contenían compensaciones no en metálico muy semejantes a las que posteriormente serían presentadas como medios de negociación.

Este fue el medio que tuvo más sostenedores, aunque fueran pocos sus practicantes. La necesidad de abordar el problema mediante una negociación generosa por ambas partes tuvo en Manuel Olivié su formulador más reflexivo:

"Nos consideramos ofendidos en nuestro honor nacional por que un pabellón extranjero ondea en parte de nuestro territorio nacional, y aceptamos como único, como exclusivo modo de borrar la afrenta, el lograr por cualquier medio, que sea el pabellón español el que le sustituya. Formuladas así nuestras aspiraciones, el orgullo de España ofendido encuentra en el orgullo inglés un obstáculo insuperable" ${ }^{34}$.

Existe una gran dificultad para clasificar los distintos programas de negociaciones, al ser la mayoria muy difusos (meras exposiciones de propósitos), al faltar a otros la mesura de la plasmación práctica ${ }^{35}$ y al no estar disponibles

32 HORACIO BENTABOL Y URETA, en su obra citada, hace una muy amplia comparación entre Ceuta y Gibraltar (instalaciones, inversiones realizadas y posibles, posibilidades comerciales y estratégicas, etc.) favorable a la primera, por lo que se muestra totalmente contrario a la permuta. Contando con el alto valor estratégico que Gibraitar conserva en el imperio británico y el único valor sentimental que para España tiene: "Vale el Peñón para Inglaterra más de lo que podemos darle a cambio, y vale para España menos que cualquiera de nuestra posesiones". OLIVE, M.: Op. cit., pág. 67. "Proponernos el cambio de Gibraltar por Ceuta es lo mismo que ofrecer a un señor un reloj de plata por uno de oro. Pero con el agravante que ambos le pertenecen". Antonio Maura citado por PLA, J.: El alma en pena de Gibraltar, Madrid, [el autor], 1953; pág. 233.

33 Fernandez Garcia, A.: Gibraltar (Ecos de la Patria); Málaga, Biblioteca Andaluza, 1884. El autor, director en 1869 de la revista Gibraltar y perteneciente al Partido Republicano, veía en Gibraltar no sólo un atentado a la soberanía nacional y al honor español si no un símbolo del empobrecimiento y decadencia de España; en su afán de combatir el efecto en lugar de solucionar la causa presentó un amplio plan de compensaciones económicas.

34 Contra la compra o permuta, «medios que revelan la pasión ciega por adquirir el Peñón [...], sería cambiar de enfermedad, pero no proporcionar remedio a la que existe", expone la fórmula de la negociación; en esencia, su propuesta es renunciar a la ampliación de la zona española en el norte de África a cambio de la devolución del Peñón. OLIVÉ, M.: Op. cit, págs. 2-3 y 66-73.

35 Álamo Álamo, J.: Gibraltar ante la Historia de España (compendio de los principales sucesos acaecidos desde su fundación hasta nuestros días); Madrid, Imp. Helénica, 1942. GonzALEz GIMÉNEZ, 
las fuentes documentales diplomáticas de quienes efectivamente elevaron a la praxis sus planteamiento teóricos. De éstos, son significativos los testimonios de los Ministros de Asuntos Exteriores del régimen franquista; si a Serrano Súner, dada la coyuntura en que se dio su cargo y su propia ideología, apenas podía llegar a pensar en una negociación, Martín Artajo ha dejado numerosas entrevistas, artículos y discursos para seguir sus planteamientos.

Estos se basaban en su fe en el Derecho internacional donde "se ofrecen mil medios de orden jurídico y práctico para hallar una solución aceptable»; anteponiendo a toda negociación el principio de soberanía española, fue el primero en apostar por la constitución de sociedades mixtas para la explotación de las instalaciones gibraltareñas ${ }^{36}$. Pero la realidad de los acontecimientos le condujeron a reflexionar sobre el poder y la fuerza en la política internacional, que permiten violar impunemente los principios del Derecho e imponer su arbitrario dominio de naciones poderosas ${ }^{37}$. Los planteamientos de Castiella se verán más adelante.

Una de las más densas exposiciones la realizó el Letrado del Consejo de Estado y Magistrado del Tribunal Supremo, José Ma Cordero Torres; dividió el problema en su dimensión civil, donde más exigente debía ser España, estableciéndose un municipio español en Gibraltar, constituido como puerto franco y de franquicias con autoridades españolas pero con servicios mixtos, garantizando las propiedades y derechos; y el militar, donde sería posible establecer una soberanía mixta por tiempo limitado, abriendo el puerto al servicio de la OTAN ${ }^{38}$.

E.: Gibraltar-El Mar-Africa-Tánger (Cuatro Consignas); Madrid, Arés, 1953. LedeSma Miranda, R.: Gibraltar, la Roca de Calpe; Madrid, Ediciones del Movimiento, 1957. SANz Briones, J.M: Gibraltar. Derechos y misión de España en la hora actual; Madrid, Ediciones del Movimiento, 1953. Sobre el espiritu que impregnaba todos estos ensayos baste citar unas palabras del último: "Que vuelta Gibraltar a nuestras manos, pero que lo haga sin sangre, sin rencor y sin estridencias" (p. 6).

36. Declaraciones al corresponsal de France Press en Londres, reproducidas en $A B C$, 21.Il.1952, pág. 15; Ya. 16.I.1952, pảg. 2.

37 Martin ARTAjo, A.: Discurso pronunciado por...; Madrid, Oficina de Información Diplomática, 1953; en este discurso, dado ante los representantes de las repúblicas americanas (12.X. 1953) ,contaba con un auditorio favorable a las tesis españolas: Argentina tenia entablado contencioso con Gran Bretaña por las Islas Malvinas, Venezuela y Brasil por las Guayanas, Guatemala por Belice y Chile por un arco del continente antártico. Es deber señalar que ninguno de estos contenciosos se ha solucionado favorablemente para la comunidad iberoamericana, y que en este contesto resalta la inoportunidad de las palabras del ex-Presidente de Gobierno español, Leopoldo Calvo Sotelo, al declarar que el conflicto de las Malvinas era para España algo "distinto y distante". La postura de Martín Artajo sobre Gibraltar en España ante la IX Asamblea de las Naciones Unidas, 1956; Madrid, Oficina de Información Diplomática, s.f.

3e CORDERo TORRES, J.M".: "Nuevas perspectivas sobre el problema de Gibraltar»; Cuadernos de Politica Internacional, $\mathrm{n}^{\circ}$ 13, enero-marzo de 1953; págs. $12-23$. 
Finalmente, en esta clasificación de los medios expuestos para la recuperación de Gibraltar se debe guardar un lugar para una postura radicalmente distinta a las anteriores, pues no apelaba a la acción española si no a la benevolencia británica, a la coyuntura propicia para su abandono o a la caída de "la fruta madura", en palabras del mismo Francisco Franco. Esta postura, entre resignada y pesimista, conocedora de la verdadera capacidad española de presión internacional ${ }^{39}$, fue además lugar común para un liberalismo decadente en su anglofilia inquebrantable ${ }^{40}$ y para una izquierda burda que asociaba toda reivindicación nacional a la derecha, antes de la guerra civil y después a la política de consumo interno del franquismo; paradójicamente, a pesar de todo "el lamentable recurso a los "truenos" oratorios (muchos, de mal gusto e inexactos) contra la "pérfida Albión"»" "41, el mismo Franco participó de dicha posición ${ }^{42}$.

\section{OBJETIVOS}

Finalmente, una vez analizados los núcleos primigenios del problema de la soberanía británica en Gibraltar y la variedad de los medios expuestos para solucionarlo, llega el momento de estudiar los fines de estas campañas. Como ya se señaló al principio del trabajo, para un mejor análisis del objetivo se ha descompuesto éste en orden a las motivaciones de los autores de las campañas y a su conclusiva cualidad directa (objetivo explícito), indirecta (efectivo) y final (subliminal).

Para ejemplificar esta división véase un caso muy concreto: en la coyuntura internacional 1940, Serrano Súñer se entrevistó con Hitler para determinar el grado de participación bélica española al lado del Eje; cuando el primero daba cuenta de las dificultades materiales que tenía la población española y señalaba que sin una ilusión concreta, claramente popular, no

39 León Román, R.: Europa trágica. II. Centinelas del Rin; Madrid, Renacimiento, 1917. Granado, M.: Los republicanos españoles y Gibraltar, [México], Finisterre, [1970].

40 ARAgon, J.: Op. cit. Misma postura adoptada por el conde de Romanones, Melquiades Alvarez, Luis de Zuleta o Alejandro Lerroux: España y la guerra; Madrid, Lib. de Vda. de Pueyo, 1915.

41 Cordero Torres, J.M.a.: «Nuevas perspectivas...", Art. cit., pág. 17.

42 Son numerosas las ocasiones en que Franco manifestó su inconformidad con la situación pero también su escasa decisión para modificarla; tómense como muestras de su posición las siguientes declaraciones: "Nosotros creemos que es una letra a plazo fijo cuyo pago podrá dilatarse, pero que al fin se cobrará», Arriba, 5.XII.1954, pág. 15. "Su situación geográfica le ha colocado moderadamente a nuestra merced; pero la gran verdad es que Gibraltar no vale una guerra. Se trata de una fruta que cualquier dia puede caer madura"; Arriba, 10.XII.1950, pág. 6. 
se podría exigir a los españoles un nuevo sacrificio, Hitler le atajó: "Esa ilusión es Gibraltar» ${ }^{43}$. El objetivo explícito para los dos personajes era la recuperación española de Gibraltar; el objetivo efectivo era la entrada de España en la contienda mundial al lado del Alemania; el objetivo subliminal era diferente entre ambos, pues iba más allá de la derrota del frente aliado, llegando a contemplar el engrandecimiento de sendas naciones por separado.

\section{a. El objetivo explícito}

Por más que en primera instancia la recuperación del territorio gibraltareño fuera el fin señalado de las más sonoras campañas diplomáticas, políticas y militares, dentro del pensamiento conservador español -y también del progresista- éste no fue el único objetivo explícito de toda la producción histórica y publicística. Según los acontecimientos políticos nacionales y la coyuntura exterior, momentos hubo donde el objetivo primero fue conseguir para España el derecho a reivindicar internacionalmente un territorio conflictivo ${ }^{44}$.

En tales casos la reivindicación misma no fue explícita, si no que pasó a desempeñar la función de objetivo subliminal, expresado en términos que declaran que lo único perseguido era el derecho a la reclamación, no al motivo de ésta.

En otras ocasiones el fin explícito es una demostración negativa, por lo general en respuesta a otra campaña en el mismo sentido pero de distinto signo. A partir de 1950, respondiendo a la pretensión británica de otorgar a Gibraltar la autodeterminación, se generó una campaña diplomática y publicistica sin precedentes; posteriormente se examinará. Desde el exterior, los republicanos contestaron las campañas interiores en lo que tenían de propaganda del régimen, por lo general con acierto, pero en ocasiones evidenciando una clara ceguera ${ }^{45}$.

\footnotetext{
${ }^{43}$ Serrano Suner, R.: Entre Hendaya y Gibraltar, Madrid, Ediciones y Publicaciones Españolas, 1947.

${ }_{44}$ "Si los españoles por evitarnos el sonrojo, nos callamos, podian los demás tomarlo como una conformidad con lo que jamás hemos aceptado" Francisco Franco en Arriba, 4.VIII.1953, pág. 3.

45 En 1940 Aranguren publicó en World Review un articulo, "The Spanishs don't want Gibraltar", lo que le valió ser criticado por sus correligionarios y ser tachado por Madariaga como ejeplar único de español que asegura que Gibraltar no pertenece a su patria; MADARIAGA, S.: España; $5^{a}$ ed., Buenos Aires, Ed. Sudamericana, 1950; pág. 768. Años después Araquistáin aseguró que con lo único que no estaba de acuerdo era con ula oportunidad de la reclamación
} 


\section{b. El objetivo efectivo}

Se define el objetivo efectivo (tomando su significado literal de real y verdadero, en oposición a dudoso o nominal) como el fin por el que se promueve una campaña explícita exponiendo los argumentos y las demandas de un modo particular y en un momento determinado, coincidente con una determinada situación nacional o internacional. La elaboración de una taxonomía del amplio espectro de los objetivos efectivos es el medio más concreto para conocer los planteamientos y divisiones ideológicas se políticos y publicistas, los verdaderos fines por los que en numerosas ocasiones se lanzaron las campañas y el peso real que el problema de Gibraltar tenía tanto en la opinión pública como en las esferas gubernamentales españolas.

La reivindicación de la soberanía española sobre el territorio gibraltareño fue vehículo de afirmación de numerosos proyectos geoestratégicos, de alineación con potencias internacionales, de campañas de consolidación interior, e incluso de identificación de la idea de España en cuanto a su territorio, civilización y proyección. Fue además, de todas las divisiones realizadas en el estudio presente sobre la cuestión gibraltareña, la más influenciada por coyunturas externas: crecimiento del imperio británico, guerra hispano-norteamericana, primera y segunda guerras mundiales, Sociedad de Naciones, organización de las ONU y la OTAN y finalmente, articulación europea en torno a la CEE y la firma del Acta Única.

La reivindicación de Gibraltar se dio, desde las divisiones ideológicas de los partidos, con escasa intensidad en la izquierda obrera, asi como en el radicalismo y el republicanismo en general; con más intensidad en el arco conservador-liberal, aunque sin ser elevada a categoría de objetivo prioritario. Donde esta reivindicación alcanzó su máxima intensidad ideologizada, y por tanto su más evidente instrumentalización, fue en la derecha tradicionalista y - a partir de la II República- fascistizante.

El carlismo tenía en la recuperación de Gibraltar uno de sus puntos básicos, sobre todo a partir del periodo de la Restauración. El testamento de «Carlos VII» exponía,

hecha": Aranguren, L.: Art. cit. Para un seguimiento de las posturas republicanas sobre Gibraltar, especialmente durante los años del franquismo, v. Granados, M.: Op. cit.; mantenía que a la altura de 1970 sólo los republicanos defendían la recuperación de Gibraltar: «El general Franco que hace sólo unos años "agarró la onda" — no más que oportunismo político, para apantallar al exterior y lograr despertar algún entusiasmo en el interior - ha abandonado ya [...] tan no le interesa que ha sacrificado a su ministro Castiella". (Pág. 16). 
"Gibraltar español, unión con Portugal, Marruecos para España, confederación con nuestras antiguas colonias, es decir, integridad, honor y grandeza; he aqui el legado que, por medios justos, yo aspiraba a dejar a mi pueblo» ${ }^{46}$.

Vázquez de Mella sintetiza la postura tradicionalista ante la cuestión de Gibraltar: su núcleo primigenio es el hecho de la posesión británica de una parte del territorio español, lo que causa una impresión de vergüenza y deshonor; para recuperarlo no se excluye ningún medio, pero se exige una determinación de gobierno. Aquí comienza el largo alegato contra la debilidad no sólo del gobierno, si no del mismo Estado, al ser aquel cómplice de quienes quieren mantener España en el estado de postración que evidencia Gibraltar ${ }^{47}$.

La postura falangista ofrece una dificultad de interpretación, al ser su plasmación práctica un seguimiento distorsionado y muy inferior a la declaración teórica. Ramiro Ledesma declaró en el punto $4^{\underline{0}}$ del programa fundacional de las JONS el propósito de "Reivindicación inmediata de Gibraltar.» Conocida es la opinión de José Antonio Primo de Rivera respecto a Gibraltar, participando de la visión más trágica sobre el tema; como no podía ser menos ante la evidencia de la irreal declaración de la "voluntad de imperio" ${ }^{48}$.

Cuando más evidentes se hicieron estas posturas, a la vez que fue más utilizado Gibraltar como objetivo explicito para conseguir objetivos efectivos diferentes, fue en las guerras mundiales, de modo muy

46 "El testamento político del duque de Madrid" en Rodezno, CONDE DE: Carlos VII, Duque de Madrid; Madrid, Espasa Calpe, 1929; págs. 257-258. Este programa de expansión no era exclusivo del carlismo, sosteniéndolo personalidades tan dispares como Castelar, Cánovas del Castillo, Moret, Rodriguez de San Pedro y en algún periodo Maeztu; dicho programa lo sintetiza asi Olivié: "Nosotros aspiramos a completar la reconquista suspendida con el descubrimiento de América y el advenimiento de al Casa de Austria [...] Aspiramos a unirnos a Portugal por el único medio que cabe entre los pueblos civilizados, la federación; y aspiramos por fin a formar con nuestras antiguas colonias en América [...] los Estados Unidos ibero-americanos". Olıvié, M.: Op. cit.; pág. 21. Africanismo, Pan-iberismo e Hispano-americanismo, tres corrientes que encontraban en la presencia británica en el Peñón la primera dificultad para su realización.

47 VAzQUez dE MELLA, J.: Temas internacionales; Barcelona, Subirana, 1934. La opinión de Vázquez de Mella recuperada durante el franquismo en GUTIÉRAEZ LASANTA, F.: "Mella y la cuestión de Gibraltar»; cap. IV de Juan Vázquez de Mella. El verbo de la Hispanidad; Zaragoza, [el autor], 1961.

${ }_{48}$ Si bien es abundante la labor reivindicativa falangista en la prensa de la época, ésta es bastante superficial. No hay un texto definitivo de alguna de sus corrientes de formación que defina apropiadamente la postura falangista ante el tema de Gibraltar. Hay que llegar hasta el final de la guerra civil para encontrar textos, oficiosos, que demarquen su posición, pero en ellos se manifiesta ya una clara voluntad de influencia en las labores de gobierno, como puede apreciarse en BARCIA TRELLES, C.: Puntos cardinales de la politica internacional española; Madrid, Ed. Nacional, 1939; $y$ Aznar y Zubigaray, M.: Politica de Inglaterra y España; s.l., Sucesores de Rivadeneyra, 1940. 
especial en la primera. El enfrentamiento entre aliadófilos y germanófilos tuvo en Gibraltar un campo de discusión que ambas posturas quisieron fuera definitivo.

Los proclives a Alemania tenían en la posesión británica de Gibraltar una $c$ lara campaña para apoyar el ingreso - o al menos apoyo- español de parte de los imperios centrales. Era claro que su victoria redundaría en beneficio de España, siendo obvia la recuperación del Peñón, que propiciaría la expansión por todo el norte africano comenzando por Tánger ${ }^{49}$.

"Gibraltar fue, naturalmente, el tema predilecto. Es fácil hacer sangrar la herida de los corazones con un recuerdo tan amargo" ${ }^{50}$. Asi trataban de desenmascarar la campaña germanófila los partidarios de una intervención del lado franco-británico; a todas las acusaciones de cinismo y soberbia inglesa, difícilmente rebatibles, los anglófilos respondieron con dos argumentos: la reivindicación germanófila de Gibraltar era una campaña puramente política y en el caso de una victoria alemana el Peñón cambiaría de manos, pero España no lo recibiría ${ }^{51}$. Por el contrario, una clara participación del lado británico abriría las puertas a la restitución del Peñón; fueron numerosas las personalidades políticas que mantuvieron esta interpretación de la posibilidad de aprovechamiento de la contienda mundial: Maura, Lerroux, Romanones, Madariaga, Melquiades Alvarez, etc ${ }^{52}$.

Este mismo argumento se utilizó alrededor de la II guerra mundial. Antes de ella y a su inicio, por los falangistas más encendidos, reproduciendo los argumentos germanófilos de veinticinco años antes ${ }^{53}$.

49 La publicistica en prensa, dado lo debatido de la cuestión, fue muy abundante; además de los artículos de Vázquez de Mella, luego reunidos en volumenes, el libro que sintetiza la postura germanófila es el del carlista MARTín MELGAR, F.: En desagravio. La guerra alemana: páginas de actualidad; Paris, Blud \& Gay Editeurs, 1915.

50 Alcala Galiano, A.: España ante el conflicto europeo, 1914-1915; Madrid, s.e., 1915; pág. 176.

"[Que] el emperador [alemán] piensa en devolvernos Gibraltar, sólo cabe en mentalidades infantiles, que esperan el triunfo del Káiser como esperan los niños a los Reyes Magos". AlCALÁ Galiano, A.: La verdad sobre la guerra; Madrid, Imp. Fontanei, 1915; pág. 36.

52 "La reincorporación de Gibraltar a España, ¿es un sueño? Aliándose España con Alemania, sin duda; con Inglaterra, tal vez no. [...] Desvanecido este argumento histórico, tan explotado por los internacionalistas, nuestra politica exterior de cordial aproximación á Inglaterra y á Francia, se robustecería con el concurso de las más vivas simpatías populares". ZULUETA, L.: Art. cit. "Por eso mismo, como anglófilo y no sólo como español, quisiera que pudiéramos sacarnos la espina de Gibraltar, que inevitablemente se nos clava en el pecho cada vez que tendemos los brazos p ara estrechar a la nación amiga". AzCARATE, G.: "Gibraltar", España, 23.IV.1915, pág. 2. MAURA, A.: Tres discursos de Maura sobre politica exterior; Madrid, AGESA, 1954.

${ }_{53}$ Gibraltar: Antologia de crónicas en torno a una jornada de emocion nacional; Barcelona. Ed. Patria, 1940. Aznar, M.: Op. cit. Carrayo, G.: Gibraltar irredento: Madrid, Hesperia, 1940. El capítulo dedicado a Gibraltar en Reivindicaciones de España de Areilza y Castiella, escrito y publicado en esta coyuntura, acaba con estas palabras: "Quizás no hay a estas alturas solución 
La innovación mayor se dio tras la guerra, cuando el régimen aprovechó el inicio de la guerra fría para presentarse como abanderado del anticomunismo; entonces la reivindicación de Gibraltar asumió los planteamientos de los antiguos anglófilos, estando dispuestos los que antes apostaron por la alianza con el Eje a defender el mundo occidental, siempre y cuando se restañaran las heridas agraviantes. Esta dinámica expositiva hizo que, por ejemplo, Carrero Blanco secundaba a Maura $y$, lo que parecia impensable, a Madariaga ${ }^{54}$.

El estudio del tema de Gibraltar en el pensamiento conservador durante el franquismo tiene las dificultades inherentes a toda profundización de una idea fuertemente mediatizada por las circunstancias políticas y la praxis cambiante en tan extenso periodo. Se debe señalar por tanto que no es este el lugar de hacer un estudio de las campañas diplomáticas llevadas a cabo, ni de las medidas políticas (como el cierre de la verja y el programa de potenciación económica diseñado para el Campo de Gibraltar), si no del objetivo efectivo que perseguían estas campañas y actuaciones, dentro del esquema que ha servido para el presente trabajo ${ }^{55}$.

Todas las dictaduras sienten la tentación de manipular las causas nacionales en su propio beneficio; el fin no es otro que crear una solidaridad nacional que reunifique la sociedad dividida que produce al implantación de la dictadura; además se busca un protagonismo a nivel internacional, que en la mayoría de las ocasiones no podria alcanzar de otro modo, y ser vehículo propiciatorio para la inclusión de la nación en un bloque determinado, la aliniación ideológica con potencias extranjeras. El franquismo con el tema de Gibraltar no podía ser una excepción, concretando cada uno de los puntos anteriores. Aunque en sí no fueran objetivos efectivos, si no medios para conseguir el fin real de la incorporación y participación española a la zona donde geográfica y culturalmente está enclavada. Como expresara Fernando Morán:

«El objetivo principal: integrar a España en el sistema capitalista occidental. La presión sobre Gibraltar iba encaminada a señalar el valor disruptivo (nuissance value) de una España desconectada y la necesidad de integrarla sin que el Régimen cambiase sustancialmente su estructura» ${ }^{56}$.

\footnotetext{
pacifica viable para el problema de Gibraltar. [...] En 1941, España, silenciosa, compacta, firme y erguida espera liquidar esta vieja cuenta que tiene pendiente con el Reino Unido". (Pág. 134)

54 Obsérvese el paralelismo existente entre MAURA, A.: Op. cit.; págs. 50-51; y DE LA COSA, J.: Comentarios de un Español: Gibraltar, Valencia, [el autor], 1952; págs. 140-143.

${ }_{55}$ Un seguimiento pormenorizado de las campañas diplomáticas y las actuaciones políticas, tanto españolas como británicas en HILLs, G.: El Peñón de la discordia. Historia de Gibraltar; Madrid, Librería San Martín, 1974.

56 MORÁn, F.: Una politica exterior para España; Barcelona, Planeta, 1980; pág. 250.
} 
En tan largo período, aun con las constantes lógicas en tema de tanta tradición, la presentación de este objetivo fue adquiriendo diversidad, con variaciones en los planteamientos, dialéctica y ámbito operativo. Durante los cuarenta se llenó de los tintes más negros del nacionalismo fascista, sobre todo hasta el fin de la contienda mundial, suavizando su postura a partir de 1947. Un caso paradigmático de esta mutación se encuentra en el prólogo de Antonio Tovar Llorente a la obra citada de Juan del Alamo, Gibraltar ante la Historia de España. En su primera edición de 1942, el prólogo toma a Gibraltar como símbolo del término del imperio español y comienzo del sistema mundial con centro en Londres; su conclusión es que la recuperación del Peñón significaría su término: «Gibraltar español, violenta y totalmente español, seria señal de que efectivamente había entrado una era política nueva. [...] Lo que no cuesta no vale, y la vuelta del Peñón habrá de ser sentida y sonada". (págs. 9-10). Pero en la segunda edición, el «Post-scritum diez años después" olvida los anteriores «tiempos de locura y esperanza" y sólo cree ya capaz de realizar la recuperación "a condición de luchar y trabajar cada día" 5 ?.

Los años cincuenta se vieron llenos de la nueva visión de la "defensa de occidente» y activados todos los mecanismos para contrarrestar la ofensiva británica, iniciada el mismo año 1950 con la concesión de un nuevo estatuto para la Roca ${ }^{58}$, y potenciada con la visita de la reina Isabel en 1954. Gibraltar fue utilizado como motivo diferenciador entre España y el resto de Europa, silenciando la diferenciación ideológica: si el mundo occidental pedía a España que contribuyera a su defensa, no se podía dejar de reclamar el fin del contencioso entre España y una de las cabezas de ese mundo ${ }^{59}$.

Significado complementario fue el intento de ampliar el sector activo en la reivindicación, utilizando Gibraltar para crear una solidaridad nacional tan necesaria en aquellos años de aislamiento. En ese sentido se llegó a crear el Dia de Gibraltar (4 de agosto) "para recordar a nuestros camaradas y a todos los españoles el dolor que sufre España por la ocupación extranjera del

57 Tovar llorente, A.: «Post-scritum diez años después"; en Juan del Alamo: Gibraltar ante la Historia de España; Madrid. Est. Tip. Sucesores de Sánchez Ocaña, 1952; pág. 14.

58 "Si los españoles hablamos ahora de Gibraltar es por que se pretende hacer creer al mundo que Gibraltar puede ser un estado autónomo dentro de la Commonwealth, y es preciso que ef mundo sepa que esto es la quinta esencia de la ficción, [...] no tiene superficie, ni agricultura, ni industria, ni medios de vida de ninguna clase, ni, lo que es más importante, población de naturales". DE LA COSA, J.: Op. cit.; pág. 148.

59 DE LA COSA, J.: Op. cit.; págs. 140-143. Reedición de la obra de Juderias, J.: Gibraltar, $2^{2}$ Ed., Madrid, Imp. Saez, 1951; en los últimos capítulos del libro, redactados por su hijo Carlos, apa. rece la imagen de una España neutral, que espera el final de la ll guerra mundial para ver premiada su dejar hacer en la Roca con su restitución. 
Peñón» ${ }^{60}$. Radio Nacional de España organizó una emisión extraordinaria «con motivo del 250 aniversario de la usurpación del Peñón» (4 de agosto de 1954). El periódico madrileño $A B C$ creó un premio anual, Gibraltar español, para destacar el mejor trabajo reivindicativo aparecido en la prensa española ${ }^{61}$.

Los años sesenta presentan una doble intervención sobre el tema. Por un lado se potencia un nacionalismo autárquico (heredero de los planteamientos mantenidos en la primera parte de los cuarenta, pero actualizados con una relectura de las prácticas de De Gaulle), que utiliza una potencia muy secundaria, como es entonces España, para enfrentarse a una gran potencia, el Reino Unido, en el principal foro diplomático mundial, las Naciones Unidas. Los puntos principales de esta campaña diplomática, dirigida por Castiella y ejecutada sobria y muy eficazmente por Jaime de Piniés, fueron los que el pensamiento conservador había elaborado en la década 1955-1965. Siguiendo el esquema de trabajo, éstos eran:

a) Vuelta al núcleo primigenio del tratado de Utrech, pero manteniendo en equiparable puesto la constatación de una parte del territorio nacional bajo control de una nación extranjera ${ }^{62}$.

b) Utilización exclusiva de la negociación como medio para conseguir la restitución de Gibraltar. Esta negociación debía ser bilateral, dado que no se quería en ningún momento la internacionalización del tema; pero se debía presionar a Gran Bretaña de algún modo para conseguir que se iniciaran conversaciones, lo que tras numerosas dudas se logró mediante la presión en la ONU y la aplicación rigurosa de los tratados, lo que cortaba toda comunicación del Peñón que no fuera marítima ${ }^{63}$. Esta negociación debía llevarse a cabo apoyándose en una serie de constataciones: vulneración británica de los tratados, disminución del valor militar de Gibraltar, agrupación humana artificial, economía fundada en el contrabando, atentado contra la integridad territorial española, mediatización de su política exterior y riesgos gratuitos en una contienda mundial ${ }^{64}$.

60 Art. $1^{\circ}$ de la Circular $n^{\circ}$ 163, (30.l.1951) de la Delegación del Frente de Juventudes, instituyendo el Dia de Gibraltar.

67 En 1956 lo ganó José Carlos Luna con “Gibraltar es España”, publicado en Sur de Málga y la Voz de España de San Sebastian; reproducido en ABC, 29.11.1957, págs. 35-36.

62 AGUINAGA, J.M. a.: Doc. cit.; "Nuestra principal razón nos la concedia el aspecto moral del problema" (p. 139) "se declarará con la adecuada solemnidad que la situación de Gibraltar era resultante de las cláusulas de Utrech -ya que nos vimos constreñidos a admitirlas- pero solamente la que se de rivara de aquellas cláusulas" (p. 112-113). Los artículos ya apuntados de José Lión Depetre aparecidos en estos años, estudiando jurídicamente a la luz del Derecho internacional el tratado de Utrech, apuntan en el reiterado incumplimiento británico, pero su validez para la restitución al control español.

63 AREILZA, J.M.ª: “Gibraltar, llave de España»; Mundo Hispánico, nº 74, mayo de 1954.

64 CORdero TORRES, J.M. . : “Nuevas perspectivas...", Art. cit. BARCIA TRELlES, C.: "Inglaterra y el Peñón...", Art. cit. AREILZA, J.M. à: Gibraltar, Madrid, Tip. Blas, [1955]. La articulación definitiva 
c) Presentar la campaña de Gibraltar como una causa nacional, con lo que se conseguían todos los fines antes mencionados, pero cuyo objetivo efectivo era la incorporación de España al mundo occidental legitimando el régimen existente; incorporación que en los años sesenta se vistió de modernidad.

A pesar del triunfo de estos planteamientos en su campaña diplomática, su posición en la balanza de poder del régimen perdió fuerza al entrar en conflicto con la segunda tendencia operante en los años sesenta en la politica exterior; la propiciada por el almirante Carrero Blanco, mucho más mesurada y consciente del lugar real que España ocupaba en el panorama internacional. La salida de Castiella en 1969 del Ministerio de Asuntos Exteriores y la ascensión de tecnócratas apoyados por Carrero cortan la línea mantenida en los veinte años anteriores, aceptando una relación de dependencia en espera de una aceptación exterior del régimen y en beneficio de una europeización modernizadora; España llamaba a la puerta de Europa, pero suavemente, tratando de molestar lo menos posible.

\section{c. El objetivo subliminal}

Señalar los orígenes del conflicto y elaborar los medios para conseguir los fines, tenia detrás toda una concepción ideológica y unos deseos -por un lado profundos, pero por generales, evidentes- de transformación de una sociedad por medio del efecto causado con el triunfo de una campaña determinada. Ese era el objetivo subliminal, el fin último y la razón final presentes en la elaboración y puesta en práctica de los programas y campañas analizados; objetivo que reunía y complementaba, sin oponerlos, los objetivos explícito y efectivo. Dado su carácter general, no son tan abundantes los objetivos subliminales que el conservadurismo español mantuvo a lo largo de los dos últimos siglos en relación a la cuestión gibraltareña. El principal, porcentualmente muy mayoritario, fue la búsqueda de un robustecimiento de la nación española.

En él se denotaban dos orientaciones. Una de afirmación, como ejercicio total de soberanía; fue la mantenida por los anglófilos durante la primera guerra mundial, por la mayoría de republicanos en el exilio y la posición

se presenta en los textos del mismo CASTIELLA, J.M.: Gibraltar en las Cortes españolas; [Madrid], s.a., 1965; y Razones de España sobre Gibraltar, [Madrid], s.e., 1966. Además de los dos Libros Rojos, presentados ante las Cortes en 1965 y 1968. 
oficial mantenida con la consecución de las resoluciones favorables de la ONU y en el inicio de las conversaciones a mediados de los sesenta.

Otra en negación, con significado de reconquista: finalización del dominio de una parte del territorio nacional por una potencia extranjera y término de ese orgullo herido que se ha señalado como origen. Este fue el fin último de la mayor parte del pensamiento conservador y de todas las campañas elaboradas durante el franquismo, salvo -en sólo aparente paradoja - la ejecutada desde las instancias de la política exterior. 